\title{
Image Restoration Strategies for the (mis-) handling of COVID - 19 Pandemic in Greece
}

\author{
Neofytos Aspriadis \\ Visiting Research Fellow, Department of Political Sciences \& International Relations \\ University of Peloponnese \\ Corinth, Greece
}

\begin{abstract}
During the COVID-19 pandemic outbreak all countries around the world used several kinds of response strategies to protect public health and control the outbreak. The main aim was to stop the disease from spreading into the community and put a pressure on the health system of the countries. However, severe measures like lockdown of cities and countries brought side-crises like economic pressure on the individuals, corporations and even the state itself. Although the Greek Government was considered to have managed the first phase of the crisis in March effectively, during the aftermath of the first phase, the complete opening of the economy and tourism, the lowering of measures leaded to the increase of new cases. The increased number of cases together with the late imposition of a new lockdown, leaded to the perception of a governmental failure. This perception mobilized direct or indirect image restoration strategies by officials of the Greek Government to maintain the positive image of their handling despite the general perceptions. This paper explores the image restoration strategies used by the prime minister of Greece for the handlings of the second phase of the pandemic in Greece. The methodology used is discourse analysis with the tools of Image Restoration Strategies by Benoit (1995) from October till December 2020.
\end{abstract}

Keywords - Crisis Communication, Covid-19 crisis, Greece, Image Restoration, Image management

SUGGESTED CITATION: Aspriadis, N. (2021). Image Restoration Strategies for the (mis-)handling of COVID-19 Pandemic in Greece. Proceedings of the International Crisis and Risk Communication Conference, Volume 4 (pp. 56-59). Orlando Fl: Nicholson School of Communication and Media. https://doi.org/10.30658/icrcc.2021.14

\section{INTRODUCTION}

During the COVID-19 pandemic outbreak all countries around the world used several kinds of response strategies to protect public health and control the outbreak. The main aim was to stop the disease from spreading into the community and put a pressure on the health system of the countries. The Greek Government was considered to have managed the first phase of the crisis in March 2020 effectively, controlling the spread of the disease.

During the second wave of the outbreak in October / November 2020, the government delayed in the handling of a new outbreak in the country. The second wave of the crisis was more severe than the first putting enormous pressure to the health system, especially northern Greece. The increased number of cases together with the late imposition of a total lockdown, leaded to the perception of a governmental failure.

At the same time, the Prime minister Kyriakos Mitsotakis provoked the public with some political movements he made like the visit in the island of Ikaria, where he and his company of almost fifty people ate at the local MP's house at a time that all restaurants are closed, and lockdown measures are in place. The second provocation was the relaxing moments the prime minister spent in the local mountain of Parnitha and took some photos without wearing a mask again in close contact with random citizens. The accusation was again the same and made negative headlines, provoking the public discourse because of his recklessness in times when strict social distance measures were in place.

These incidents provoked secondary crises that threaten the image of the Prime Minister directly and the government. In time of crises the positive image and the approval of the crisis manager are enhancing trust and make stakeholders follow the instructions and the narrative. Therefore, such threats to the image of the crisis leadership may lower the rally effect around the crisis managers.

This paper examines the image restoration strategies used by the prime minister of Greece to defend himself against the accusations by the people and the political opposition for his "wrongdoings". The first case (late imposition of measures for the lockdown) was considered a managerial problem leading to the perception that the government lost track of the crisis management process and relaxed. The other two cases affected the public discourse because it showed a perception that the Prime Minister was above the law. The Prime Minister tried to address all accusations either through his public speeches or interviews. The first section elaborates on the Image restoration theory, the second on the methodology used 
and the third presents the results of the case study.

\section{IMAGE RESTORATION IN CRISIS COMMUNICATION}

As soon as a political crisis breaks out, questions on responsibility occur. Usually, the media are those to initiate the blame game, trying to find the responsibility among the actors. Such blame attributions play a significant role and have great influence in public opinion [8]. Public apologies abound-from one of the most notorious, former president Bill Clinton's confession and apology for an extramarital affair with White House intern, Monica Lewinsky, to a myriad of other politicians, religious leaders and celebrities caught up in sex, financial or other kinds of scandals [6]. In a crisis there is always accountability to any of the responsible parties and this motivates strategies of apology or image restoration.

In politics, blames and accusations are very common in the public discourse. A crisis can be perceived as a stand-alone, ad-hoc disturbance in an otherwise well-functioning system, or as an embedded incident, epitomizing a much larger systemic failure [3]. For political elites, attribution of blame involves strategic calculations and may be observed to function as "political weapon" or a vehicle of public mobilization [7]. According to Ryan [9], an accusation can be established against a person's character or against his political positions. In both cases, the restoration of the image is necessary to maintain the reputation of the persons or organization under attack.

Usually, through the use of image restoration strategies, the aim is to avoid the blame. Reactive blame avoidance describes political strategies displayed after a problematic issue has appeared on the public agenda and related blame has to be addressed [5].

Benoit's [1] typology offers a concrete way of managing rhetorically and strategically a severe image crisis. A person may choose how to handle a particular situation either by using image restoration strategies and try to evade responsibility or to acknowledge the accusations and apologize. However, while public apologies, whether from governments or organization leaders are uncommon, and some don't include compensation, studies show that they are helpful in repairing and restoring relationships [6].

Benoit's [1] typology is consisting of five main strategies that may avoid blame or restore one's image. These are Strategy of Denial, Evading Responsibility, Reduce offensiveness, corrective action, and mortification. Denial is mainly for offenses for which there is insufficient information to the responsibility implicated [4]. The Strategy of Denial consists of simple denial of guild and of denial of responsibility for the wrongdoing [10]. There are four ways to evade responsibility: either by claiming provocation from another party, or by alleging lack of adequate information or control of important factors affecting the situation. Another way is to attribute the wrongdoing to accident, coincidence or random circumstances [1]. To reduce offensiveness a very common strategy is to Bolster one's image. The defender tries to bolster his image and his credibility towards the public by highlighting previous positive images and attitudes [10]. This strategy may prove more effective if the positive experiences outlined show a relevance to the present situation [1]. With Minimization the defender seeks to convince the victims of the act that the act itself did not have so painful results as originally thought [2]. On the other hand, differentiation refers to the ability to seperate certain aspects of the issue from more negative ones (ibid). Transcendence can reframe the perception of an act presenting it in a different more positive context. Specifically, the strategy is part of the reframing process and aims to give a new interpretation to the negative act with a view to give broader and more positive regulatory framework [1];[10]. Counterattack is also a very common strategy used to evade responsibility, especially in politics. The defender can use Counterattack either by its own or in combination with Denial, yielding substantial fault to the opponent or accuser [4]. Last but not least, with compensation the defender seeks to bribe the victim, however, if the latter accepts the offer, the wrong-doing can be balanced and restore the reputation of the offender [1].

\section{METHODS}

The methodology used in this study is the Qualitative Content Analysis with elements of rhetorical analysis in the speeches and interviews of the Prime Minister for the three cases in question. The coding procedure was based on the pre-existing typology of Benoit [1] on Image restoration strategies. The coding procedure was established in the environment of MAXQDA software. The coded segments were then quantified with the help of the software in order to establish a clear view on the frequency of the appearance / use of the strategies. The quantification of the qualitative analysis would show the dominant strategy/-ies used by the Prime Minister illuminating the strategic - mental thought of decision making.

The paper focuses on three central events of (mis-) handling of situations. The first is the delayed decision to move to a second lockdown in October, the second is the Prime minister's relaxing moments in Parnitha and the third is the Prime ministerial visit in Ikaria in February 2021, which is typically away from the second wave but is closely related to the other two incidents. Cosequently, the period of study for the mishandling of the second wave and the relaxing moments in Parnitha is the timeframe of October 2020 - December 2021 and for the visit in Ikaria, January - February 2021. 


\section{RESULTS}

\section{IMAGE RESTORATION STRATEGIES FOR THE (MIS-)HANDLING OF THE SECOND WAVE}

In October 2020 after an almost four-month period of low new coronavirus cases during the Summer, the situation got out of hand whereas at the same time the governmental response was slowin its reactions to the so-called second wave of the pandemic. With a record of 3000 new daily cases in the beginning of November, the second wave hit Greece "under the radar". The initial measures for containing the second wave were implemented in the end of October with the imposition of a lockdown in Northern Greece, which was hit more at that time. Almost a week later, whole of Greece was put under a three-week lockdown, which lasted almost two months and brought the health system to its knees.

The accusations coming from public opinion and the opposition parties related to the late imposition of containment measures which leaded to more deaths than in the first wave. It was the first hit in the reputation of the Greek Prime Minister and challenge to the governmental crisis management policy since the beginning of the pandemic in Greece.

The main strategy used by the Prime Minister was Bolstering. Through this strategy he aimed to defend his position and political movements till that time. Another strategy used was an indirect blame shifting to the committee of experts that was advising all this time the government on the measures that needed to be taken. He admits indirectly that he should take the decision to close the country but at that time there were no requests by anyone to move to a lockdown. The indirect blame shifting aims at minimizing the responsibility of the Prime Minister. Another strategy used was differentiation. Even if considered a late response to the new wave, the Prime Minister presents the measures taken as if they were taken in time. The argument is based on the European practice followed at that time, when the most countries were also late in taking effective response measures. The differentiation strategy served to reduce the offensiveness since Europeans are doing worse than Greece and therefore the decision to move to a new lockdown at this moment was the right one.

In sum, he does not address the accusation directly but tries to defend his decisions through bolstering his image and differentiate from worse cases that happens in other countries.

\section{IMAGE RESTORATION STRATEGIES FOR THE RELAXING MOMENTS IN PARNITHA}

In December, the Prime Minister during his relaxing moments visited the nearby Parnitha mountain. During his sporting activities he took a photo with other visitors without wearing a mask, which was obligatory at that time. The photo was posted on his personal social media account probably by himself to advertise his relaxing moments and the discussion with citizens. However, the absence of a mask and the close contact with random people provoked the public opinion on social media for being "above the law". Accusations were also made by the political opposition and expanded also to the fact that he went for cycling outside the area of his residence, which was thought until that time that it was prohibited. The Prime Minister answered directly during an interview a few days later.

This time, the Prime Minister acknowledged responsibility for agreeing to be photographed without a mask but not for the second accusation, for going for cycling. The strategy used was differentiation between two parts of the accusation and offered corrective action by acknowledging that in the future he will wear a mask in photoshoots with other citizens. He also used bolstering by saying that he has high expectations from himself and that he is a very carful person. He offers no real apology though and he does not admit the guilt directly.

Although this strategic choice of not admitting guilt was not very harmful at this stage, it forms a precedent that accumulates negative reputation for the future and may be combined or arise in future events.

\section{IMAGE RESTORATION STRATEGIES FOR THE OFFICIAL VISIT IN IKARIA}

Such an event was the official visit in Ikaria held in February with the excuse to oversee the local vaccination process and solve local issues concerning civil protection. The company of the Prime minister's visit was consisting of almost fifty people which were considered a threat for spreading the virus to the island. In addition, during the stay the prime minister and his company was invited to a launch at the local member of parliament's house at the centre of the island. Videos released from the crowding terrasse provoked again public opinion and the main opposition who accused him for "not following the law" and "provoking the law-biding citizens".

Again, the Prime Minister answered by himself through an interview a few days later. He accepted responsibility for the "picture" of the crowded place that provoked the citizens and offered corrective action by saying that he will revise the number of people accompany him in the official visits and take other precautionary measures. In addition, he counterattacks the main opposition party for accusing when at the same time they organize protests with much more people in Ikaria but also in the capital. Furthermore, he accuses the main opposition leader Alexis Tsipras of helding meetings and visits in shops and closed spaces without wearing a mask. Last but not least, he uses again the strategy of bolstering by saying that the crisis management policy of his government is proving effective since the only thing the opposition may say is for such secondary things.

Once again, the acknowledgement of responsibility was indirect as he did not acknowledge responsibility for the actual accusation, which was not following the law and taking preventive measures in times where other citizens are punished for similar or even smaller behaviours. In addition, the restaurants are closed, and the prime minister is eating in a balcony with fifty people. The image of that provoked the people that needed to close their restaurants or even those who suggested similar measures for reopening. He tries to reframe from all these accusations and focus on the oppositional discourse. 


\section{CONCLUSION}

Looking at the findings all together, the prime minister at least in the two of the three examined cases does not think he has done something wrong. However, he uses an image restoration strategy in order to bolster his image. In the third case, nevertheless, he uses the strategy of counterattack just to remind the opposition that they do the same making an indirect use of the ad hominem "et tu quoque".

The Prime minister's discourse for the mishandling of the second pandemic wave in November 2020 points more to the direction of a strategy of transcendence. Apparently, the failure to effectively manage the pre - crisis phase and contain the spread in time leaded to a second general lockdown, which was considered as a failure due to the burden of the economic consequences.

The increased use of Bolstering strategies and especially self - praise shows that the prime minister tried to restore his image towards society in an attempt to transcend from explaining why the situation got from "We are far away from a lockdown" (Chardalias, 16.10.2020) to the imposition of a lockdown 15 days later.

In the wrongdoings concerning the relaxing moments and the photos without masks in Parnitha mountain the Prime Minister did not acknowledge any wrongdoing but the fact of not wearing a mask during the photoshoot with the citizens. Instead of acknowledge responsibility he tried to transcend with bolstering and persuade the public that he follows the measures and that this was an sole event due to relaxing moments.

In contrary, the visit in Ikaria island the strategy changed but again did not ackowlegde responsibility for the acual wrongoing. This incident was more severe than the first one, but it was not able to damage the prime minister's reputation. However, such small negative events work accumulatively forming specific images in the mind of the people which may arise in future circumstances. When something really negative will happen, these events may practically disable the effect of a bolstering strategy.

\section{Author Biography}

Aspriadis Neofytos, PhD from the Department of International \& European Studies, University of Piraeus. Visiting Research Fellow, Department of Political Studies and International Relations, University of Peloponnese, Greece. asprto@gmail.com

\section{REFERENCES}

[1] Benoit, W. L. (1995). Accounts, Excuses and Apologies, A theory of Image Restoration Strategies. State University of New York Press. New York.

[2] Benoit, W. L. (2018). Crisis and image repair at united airlines: Fly the unfriendly skies. Journal of International Crisis and Risk Communication Research, 1, 11-26. https://doi.org/10.30658/jicrcr.1.1.2

[3] Brändström, A., Kulpers, S., \& Daléus, P. (2008). The politics of tsunami responses: comparing patterns of blame management in Scandinavia.

[4] Hearit, M. K. (2006). Crisis Management by Apology, Corporate Response to Allegations of Wrongdoing. Lawrence Erlbaum Associates Publishers.

[5] Fernandes, I., Almeida Lopes Fernandes, G., Fernandes, G., \& Salvador, P. I. (2021). Blame avoidance: The costs of weak accountability in a health disaster. Available at SSRN 3790705.

[6] George, A. M. (2020). Sorry is not enough: Apology as a crisis management tactic. Proceedings of the International Crisis and Risk Communication Conference, Volume 3 (pp. 10-16). Orlando FL: Nicholson School of Communication and Media. https://doi.org/10.30658/icrcc.2020.3

[7] Jennings, W. J. (2005, April). Blame attribution and blame management: iraq in comparative perspective. In Conference: Blame Management and Blame Avoidance, Granada, Spain (pp. 14-19).

[8] Knobloch-Westerwick, S., \& Taylor, L. D. (2008). The blame game: Elements of causal attribution and its impact on siding with agents in the news. Communication Research, 35(6), 723-744. https://doi.org/10.1177/0093650208324266

[9] Ryan, H. (1982). Kategoria and apologia: On their rhetorical criticism as a speech set. Quarterly Journal of Speech, 68, 254-261. https://doi.org/10.1080/00335638209383611

[10] Ware B. L., \& Linkugel, W. A. (1973). They spoke in defense of themselves: On the generic criticism of apologia. Quarterly Journal of Speech, 59, 273-283. https://doi.org/10.1080/00335637309383176 